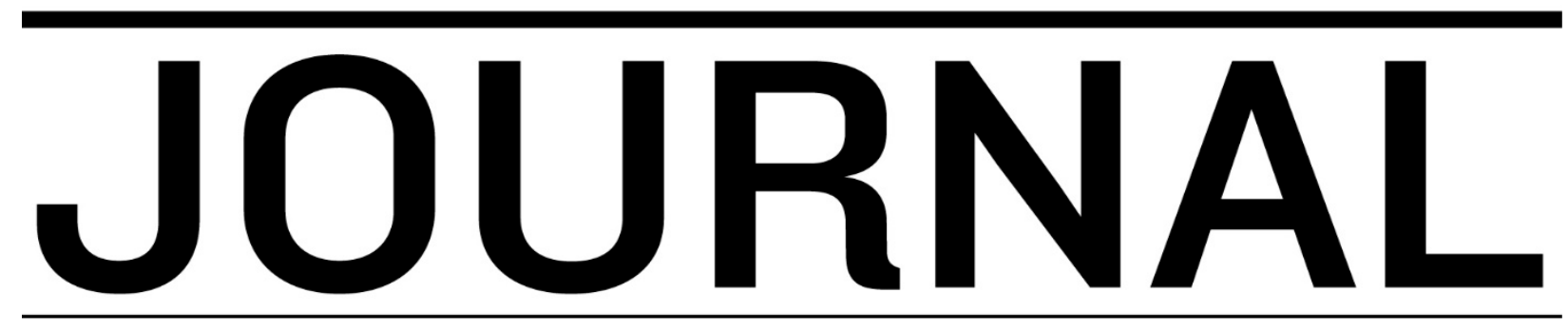

\title{
OF LIVING ARCHITECTURE
}

A GREEN ROOFS FOR HEALTHY CITIES PUBLICATION

\section{An ecomimicry design approach for extensive green roofs}

\section{Caroline Nash ${ }^{1, *}$, Mihaela Anca Ciupala ${ }^{2}$, Dusty Gedge ${ }^{3}$, Richard Lindsay ${ }^{4}$, Stuart Connop 5}

${ }^{1}$ Research Assistant, Sustainability Research Institute (SRI), University of East London, UK

${ }^{2}$ Senior Lecturer, School of Architecture, Computing \& Engineering, University of East London, UK

${ }^{3}$ Director, Green Infrastructure Consultancy, UK

${ }^{4}$ Head of Environmental \& Conservation Research, SRI, University of East London, UK

${ }^{5}$ Senior Research Fellow, Sustainability Research Institute, University of East London, UK

*corresponding author: c.nash@uel.ac.uk

\begin{abstract}
Extensive green roofs (EGRs) have been promoted as a multifunctional urban green infrastructure (UGI) solution that can ameliorate some of the negative environmental effects associated with urbanisation and provide habitat for wildlife. To date ecological EGR research remains limited, yet studying and understanding the ecology and ecological processes of these novel urban ecosystems could maximise their potential to conserve biodiversity and deliver multiple ecosystem services to urban areas. Here we present an overview of how a novel 'ecomimicry' approach can be used to ensure that locally important habitats are created and restored as part of urban green infrastructure strategies, and that biodiversity is embedded at the heart of EGR design. This can help urban developments meet sustainability targets and contribute to the goal of no-net-loss of biodiversity. Conserving urban biodiversity through ecomimicry will increase opportunities for urban communities to reconnect with nature and improve the quality of life for people in cities.
\end{abstract}

Key words: ecomimicry, biodiversity, extensive green roof, ecological design

This peer-reviewed Article is provided free and open-access. 


\section{INTRODUCTION}

Extensive green roofs (EGRs) have been promoted as a multifunctional urban green infrastructure (UGI) solution that can ameliorate some of the negative effects associated with urbanisation (Oberndorfer et al. 2007). Studies have shown EGRs can deliver a range of ecosystem services (ES) including stormwater amelioration and pollution (Schroll et al. 2011; Nagase and Dunnett 2012; Speak et al. 2012), urban heat island mitigation (Alexandri and Jones 2008; Bowler et al. 2010; Lundholm et al. 2010; Susca, Gaf, and Osso 2011) and energy conservation (Wong et al. 2003; Castleton et al. 2010). A further key driver for EGR implementation has been to provide habitat for wildlife. In comparison to other areas of EGR research such as engineering design, studies on the ecology of EGRs remains limited (Blank et al. 2013; Williams et al. 2014; Thuring and Grant 2016). This is perhaps surprising as EGRs are essentially novel living ecosystems that once installed, are subject to ecological processes such as climatic factors (for instance wind, rain, temperature) and interactions with other organisms (Sutton 2015). Since there is compelling evidence of the positive role biodiversity plays in ecosystem functioning and human wellbeing (Millennium Ecosystem Assessment 2005; Balvanera et al. 2006), studying and understanding the ecology and ecological processes of EGRs should therefore be a research priority. Maximising the potential for EGRs, and other UGI, to conserve biodiversity will bring multiple ES to urban areas because healthy, biodiverse ecosystems tend to be more productive and resilient (Cardinale et al. 2012). We present an overview of how a novel 'ecomimicry' approach can be used to ensure that locally important habitats are created and restored as part of urban green infrastructure strategies, and that biodiversity is embedded at the heart of EGR design.

\section{EXTENSIVE GREEN ROOF TYPOLOGIES}

As cities have become more populated, policy has increasingly advocated densification of urban areas, reducing green space provision at ground level (Dallimer et al. 2011). Green roofs offer an opportunity to provide greenspace in high-density urban areas without reducing available space at ground level. As understanding increased on the capacity of green roofs to deliver environmental benefits, they became a mainstream technology (Moulton and Gedge 2017). Due to their lower cost, weight and maintenance requirements, extensive green roofs became the commonest type of green roof installation. When evidence of the ecosystem service benefits of EGRs led to their more widespread implementation, a green roof industry developed, resulting in purpose-built EGRs that followed a fairly standardised design (Thuring and Grant 2016). Commercial EGRs became multi-layered systems comprising four elements: a waterproof rootresistant barrier, a drainage layer, growing medium, and plants. Two main EGR typologies have since emerged: 'Sedum' and 'biodiverse'.

\section{Sedum extensive green roofs}

Sedum EGRs have become the predominant industry-standard design which evolved into an 'off-the-shelf' system, built with a uniform shallow substrate layer, and a Sedum-dominated vegetation layer (Cook-Patton and Bauerle 2012). Sedum and succulent plants were originally selected for use on EGRs because they could endure exposure and prolonged drought (Snodgrass and Snodgrass 2006), a particularly important characteristic for EGRs that were 
primarily being designed as free-draining Sustainable Drainage Systems (SuDS). Also, Sedum spreads rapidly, providing $100 \%$ coverage on EGRs in a short time, reducing initial plant installation costs (Monterusso, Bradley Rowe, and Rugh 2005). The uniform, blanket vegetation coverage of Sedum EGRs has been favoured due to its perceived 'neat' visual aesthetic (Jungels et al. 2013) and the desire for an instant 'green' effect.

Sedum EGRs can provide habitat for biodiversity, even if not intentionally designed to fulfil nature conservation objectives (Coffman and Waite 2011). However, from an ecological perspective, homogenous Sedum EGRs provide a restricted range of benefits for biodiversity because they often comprise plants from a single genus (Sedum), offer limited structural diversity and have short-lived flowers (Kadas 2006; Gedge et al. 2012; Rumble and Gange 2013; MacIvor, Ruttan, and Salehi 2015). Furthermore, Sedum dominated systems do not reflect the character or distinctiveness of regional plant communities, as most species would not be native to the regions where they have been installed. In nature, Sedums typically form part of an early successional mosaic, rather than a predominant vegetation cover. Whilst a literature review of suitable green roof vegetation for North American ecoregions found Sedums to be a reliable and successful genus for most regions (Dvorak and Volder 2010), some species have been shown to perform poorly in warm climates in the US (Klein and Coffman 2015). Research has indicated that Sedum dominated planting on EGRs may also constrain environmental performance, for instance in terms of providing ES such as urban cooling and stormwater capture (Lundholm et al. 2010; Blanusa et al. 2013).

\section{Biodiverse extensive green roofs in the UK}

In response to increasing interest in using EGRs to support nature conservation and ES targets (Grant, Engleback, and Nicholson 2003; Oberndorfer et al. 2007), an alternative green roof typology the 'biodiverse' EGR emerged. The ideology behind biodiverse EGRs was that the design would specifically benefit wildlife. In the UK, an important driver for biodiverse EGR design and implementation was conservation of a bird called the black redstart Phoenicurus ocruros (Gedge 2003; Ishimatsu and Ito 2013). An increasingly rare breeding bird in the UK, its population was mostly concentrated in urban brownfield sites, with London being a hotspot for the species. In mainland Europe, where the species is quite common, it inhabits open, stony, sparsely-vegetated habitats on craggy terrain. In the UK the species utilised a similar habitat niche, but almost exclusively within derelict brownfield sites in cities.

Brownfield sites are previously-developed land that has been abandoned or become unused. They encompass an array of former uses such as railway lines, quarries, waste tips, mines and power stations, and typically occur in developed urban areas. Sites of recent origin covered with impervious artificial surfaces tend to be of limited ecological value, but longer-standing brownfield sites that have been spontaneously colonised by vegetation can develop communities analogous to natural habitats such as flower-rich grassland, saltmarsh and heathland (Eversham, Roy, and Telfer 1996; Eyre, Luff, and Woodward 2003). In addition to being home to the black redstart, these sites have been found to support high biodiversity and important populations of other rare and threatened species (Bonthoux et al. 2014). As widespread urban regeneration in the UK resulted in much urban brownfield land being lost to 
redevelopment, survival of the black redstart in the UK looked precarious (Gedge 2003). In response to this situation, a black redstart 'action plan' was created that promoted using biodiverse EGRs as a solution for providing habitat within urban developments for black redstarts (Gedge 2003). Informed by pioneering Swiss green roof research (Brenneisen 2003, 2006), these novel biodiverse EGRs were designed to emulate the arrested pioneer communities found on brownfield sites, to recreate a suitable habitat niche for black redstarts, and for the invertebrate communities on which they depend (Gedge 2003; Kadas 2006).

In contrast to Sedum EGRs, biodiverse EGRs have typically been constructed using lownutrient, recycled aggregates at various depths to establish a mosaic of open, flower-rich vegetation and areas of bare ground. When biodiverse roofs were first developed, it was common practice to allow the roofs to be colonised by vegetation naturally, so that local plants appropriate to the site could develop (Gedge et al. 2012). Subsequently, seeding with locally appropriate, and ideally locally-sourced wildflowers has become standard practice, primarily to assist a range of native plants to establish, and augment the various species that arrive through spontaneous colonisation (Gedge et al. 2012). Figure 1 shows an example of an industrystandard Sedum roof (a) and a biodiverse roof (b) to illustrate the contrast in habitats that can result from these two approaches.

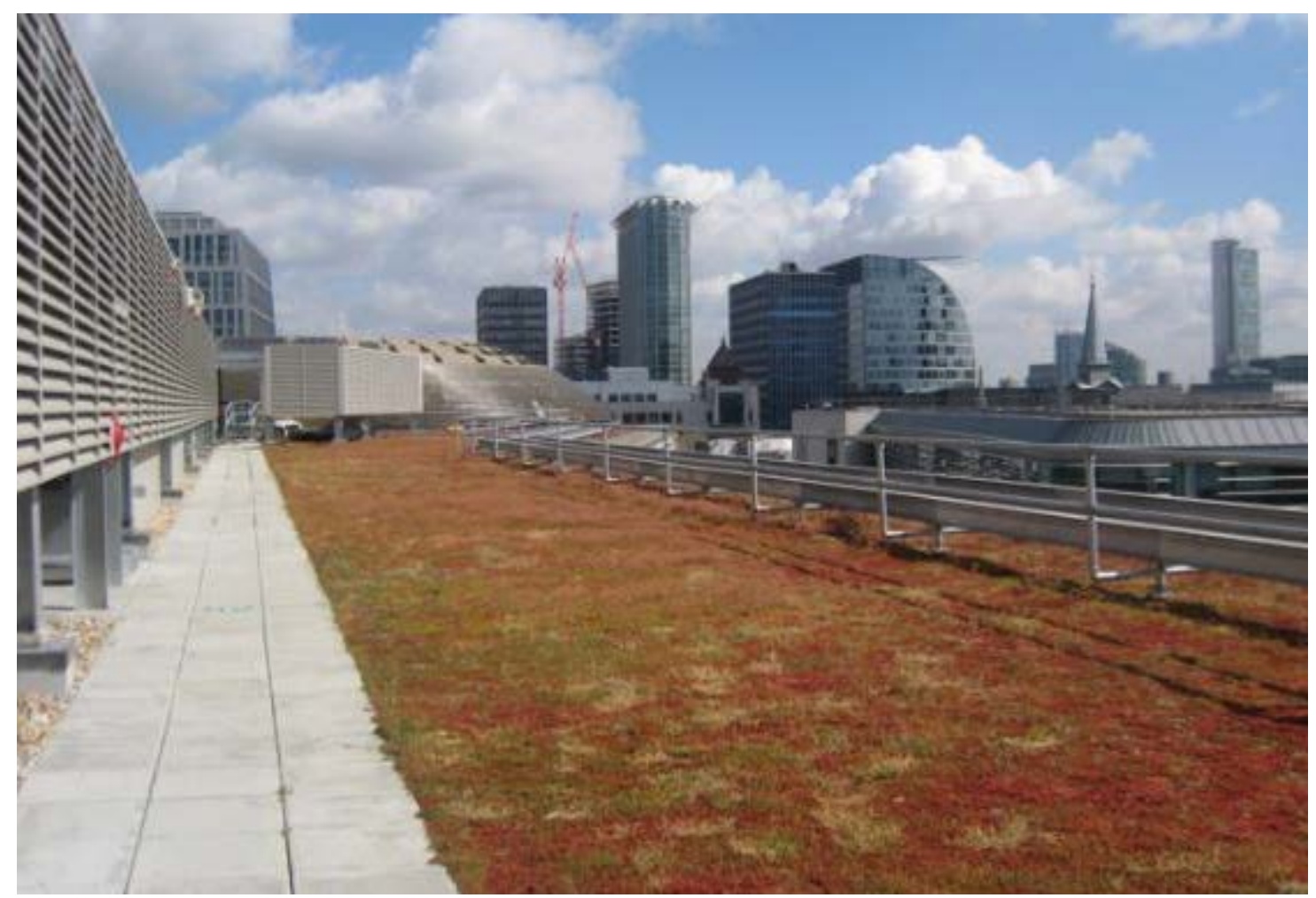

(a) 


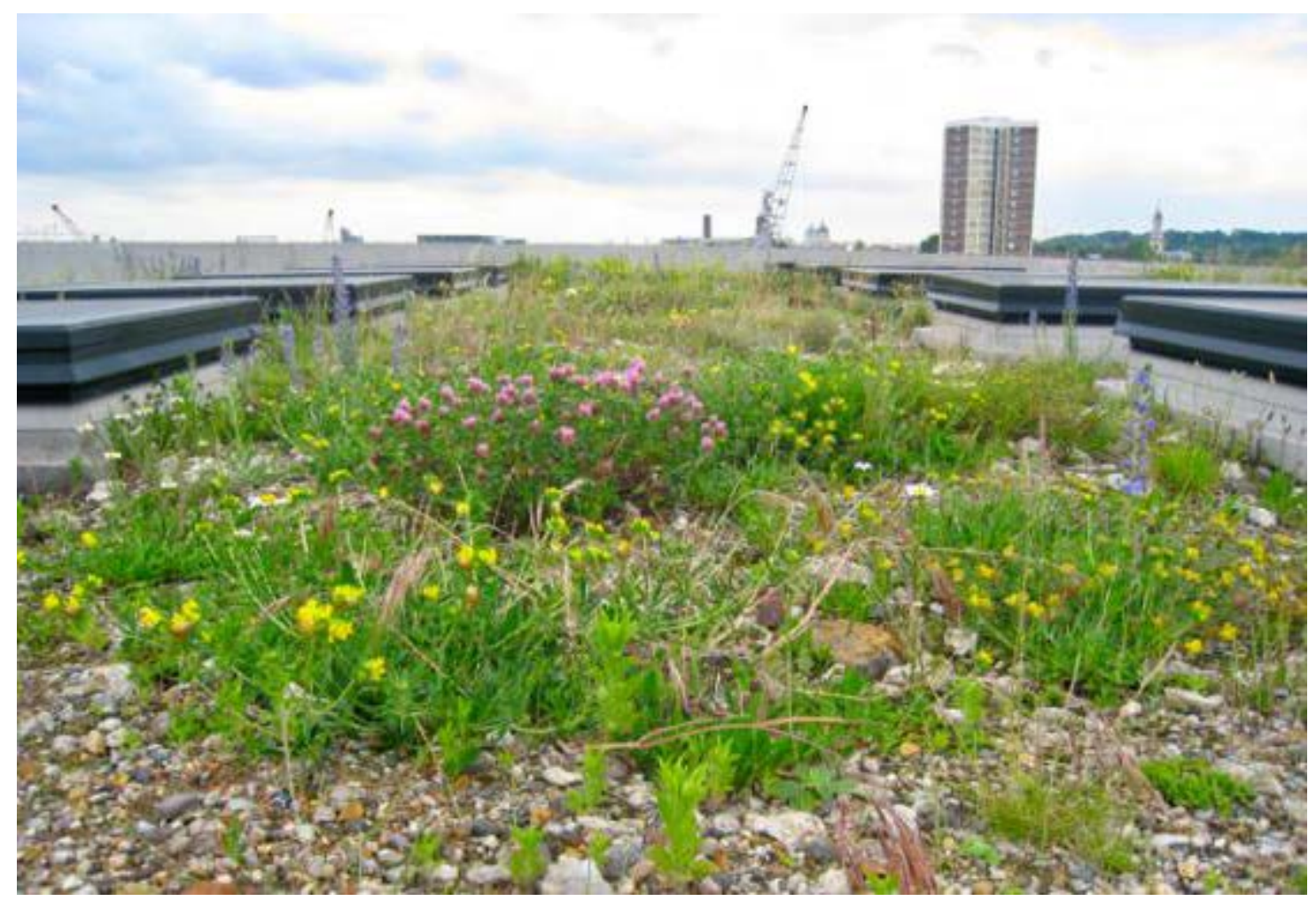

(b)

Figure 1. Examples of (a) an industry-standard Sedum EGR, and (b) a biodiverse EGR. Image (a) Sedum EGR in the City of London; image (b) biodiverse EGR on Laban Dance Centre, London. Images (C D. Gedge.

Research in the UK has shown that biodiverse EGRs can provide surrogate habitat for brownfield invertebrates, including nationally or locally rare and scarce species of conservation importance (Kadas 2006; Nash et al. 2016). A study investigating the value of green roofs for bats recorded significantly higher levels of bat activity over biodiverse EGRs (Pearce and Walters 2012) indicating they have enhanced value for a variety of species inhabiting in cities.

\section{Biodiverse extensive green roofs in Europe, North America and beyond}

Some of the earliest research on biodiverse EGRs was carried out in the Swiss city of Basel in Northern Europe, looking at the bio-ecological potential of creating structured microhabitats and using natural regional substrates on EGRs to increase faunal diversity (Brenneisen 2003). The research found EGRs designed this way provided habitat compensation for rare and endangered species. From this study, Swiss biodiverse EGR design has primarily focused on simulating endangered alluvial grassland habitat using reclaimed local, native substrates such as gravel and topsoil in preference to engineered green roof substrates (Brenneisen 2006). Most published research on biodiverse EGRs in Europe has been in temperate regions, but one study identified four vegetation types associated with (semi)-natural open habitats in Southern France that could inspire biodiverse EGR design for the (sub)Mediterranean region (Van Mechelen, Dutoit, and Hermy 2014).

A review of North American research found a growing body of work investigating suitable native plant species for EGRs, but reported that most studies were from the perspective of 
improving environmental performance, rather than achieving biodiversity conservation goals (Dvorak and Volder 2010). Nonetheless, Lundholm's (2006) proposed 'habitat template' model encouraged a more ecological approach to EGR design, based on concepts outlined in Larson et al.'s (2004) 'urban cliff hypothesis' - the theory that species which colonised cities were preadapted to inhabit the urban built environment because they originated from rocky outcrop habitats. Thus, the habitat template approach promoted plant selection from exposed, rocky, infertile natural habitats because these have adapted to conditions analogous to those typical to EGR systems (Lundholm 2006). This has led North American researchers to investigate candidate native plant species from natural analogue habitats such as Nova Scotian rocky coastal barren habitats (Lundholm et al. 2010; MacIvor, Ranalli, and Lundholm 2011), and alver grasslands and Lake Ontario dunes (Mandel, McCoy, and Liss 2016). There has also been increasing interest in understanding the affinities between conditions that define native North American prairies and EGRs, as prairie ecosystems support high species diversity, and contain plant species adapted to stressed, low-nutrient conditions akin to those on EGRs (Sutton 2008; Sutton et al. 2012; MacDonagh and Shanstrom 2015). Shortgrass prairies, in particular, have functionally shallow substrate depths, and are characterised by an environment that can be hot, dry, windy and drought-prone (Sutton 2008; Sutton et al. 2012; MacDonagh and Shanstrom 2015). As they have become more widely adopted, and successful strategies for their establishment reported (Sutton 2013), prairie-based EGRs appear to be the burgeoning biodiverse EGR design in North America. Research investigating bee communities on Chicago EGRs reported that a prairie-based EGR supported greater bee diversity and abundance, and higher plant diversity than Sedum-dominated EGRs in the study (Tonietto et al. 2011), indicating the potential for biodiverse prairie EGRs to deliver enhanced nature conservation benefits.

Further afield, EGRs have been recommended as habitat for biodiversity in Australian cities and as native Australian grasslands have similar characteristics to North American prairies, it has been suggested these could potentially offer a suitable habitat template for biodiverse EGRs in Australia (Williams, Rayner, and Raynor 2010). Nonetheless, an EGR study testing several native Australian plants from plains grasslands, coastal dunes and salt lake communities reported mixed results in terms of survival on an EGR in the absence of supplementary irrigation, and questioned the applicability of the habitat template approach for extreme hot, dry climates (Rayner et al. 2016). In Asia, researchers have begun studying the plant communities of rocky sea coasts as a potential habitat template for irrigated biodiverse EGRs in Japan (Nagase and Tashiro-Ishii 2018).

\section{Building on current design approaches}

Whilst one of the original aspirations for biodiverse EGRs was that they would have a heterogeneous character (Thuring and Grant 2016), there is a risk that these too could become a relatively standardised design as installers and clients seek to use familiar tried and tested models or plant palettes, rather than developing bespoke designs that are locally-attuned. The use of habitat templates and plant traits have been important for developing biodiverse EGR designs based on naturally occurring habitats. Nonetheless, when suitable habitat templates and 
analogues have been identified, there can be a tendency for designs to be applied universally across geographical regions, with the resulting biodiverse EGRs not reflecting the specific local ecological context in which they are located. For example, Sutton et al. (2012) suggested moving prairie-based habitat templates beyond their native region for use on green roofs in temperate areas. Whilst prairie plant assemblages appear to be a resilient and promising option for biodiverse EGRs, and may successfully survive in various regions, this type of universal approach risks contributing to biotic homogenisation, and could have negative implications for how well biodiverse EGRs perform in relation to nature conservation targets. Furthermore, given the wide range of ecoregions they cover, even a standardised design for prairie-based EGRs for North America would miss opportunities to embed locally or regionally distinctive features or communities into EGR designs, which could result in sub-optimal ecological functionality for local wildlife.

Since heterogeneity within and between urban green spaces has been positively linked to the coexistence of diverse assemblages (Lepczyk et al. 2017), it seems logical that relying on a uniform or universal design for EGRs could be detrimental to the aim of conserving biodiversity. To date there has been very limited empirical research specifically investigating opportunities to broaden the range of habitat types and niches that could be provided by biodiverse EGRs (Nash 2017; Walker and Lundholm 2018). Consequently, there is a danger that even biodiverse EGR design could become homogenised, and opportunities for biodiversity not fully realised. Thus, it has been recommended that research and practice involve greater consideration for the creation of habitats through developing diversity in green roof elements and structure (Thuring and Grant 2016). Using an 'ecomimicry' approach to EGR design could provide a technique to address this challenge.

\section{ECOMIMICRY}

\section{The ecomimicry concept}

The term ecomimicry has been used to describe the concept of design inspired by nature (Marshall 2007). It draws upon the ideas of biomimicry (Benyus 1997), which advocated learning from organisms, ecosystems and natural processes, and then emulating their natural forms, functions and strategies in innovation and design. Whilst biomimicry takes inspiration from nature, the outcomes have not always been environmentally or socially responsible, and this, according to Marshall (2007), is a distinguishing difference between ecomimicry and biomimicry. Ecomimicry not only takes inspiration from organisms and ecological systems, but it also seeks to develop environmentally sensitive solutions that involve and serve human and natural communities (Marshall 2007). A further difference is that ecomimicry specifically considers local ecology as the basis for design and innovation, the rationale being that local plants and animals will have evolved with, and be adapted to local conditions, and therefore would be most resilient to local environmental challenges. As Marshall (2007) posits, if innovations are to be sustainable, then taking "inspiration from local species is likely to be most fruitful”. 
The ecomimicry approach as proposed by Marshall (2007) has been adopted, adapted and studied as a mechanism to maximise the biodiversity value of EGRs and other UGI (Connop et al. 2016; Nash 2017). Here the term ecomimicry has been used to describe an approach that takes inspiration from locally typical, regionally important habitats and species, and then embeds that ecological knowledge into UGI design. In some respects, ecomimicry has affinities with the habitat-template approach (Lundholm 2006), but it specifically encourages examination of the local landscape as inspiration for habitats that can function as analogues on EGRs. As part of this, an ecomimicry approach also looks for innovative ecological engineering opportunities to alter the main EGR components (vegetation, substrates, drainage), to try to incorporate important biotic and abiotic features of locally distinctive, regionally important habitats into EGR design. As such, ecomimicry represents a progression of the habitat-template concept which, it has been suggested, may work best as a course filter for selecting suitable generalist plant species for biodiverse EGRs (Lundholm and Walker 2018).

A key objective of the ecomimicry approach is to avoid UGI designs that perform single or narrow functions i.e. for visual amenity or SuDS, or which rely on a one-size-fits-all approach. Instead the aim is to design and create EGRs and UGI that provide locally-attuned and ecologically functioning habitat, because well-functioning ecosystems are typically more effective at delivering multiple ES. As such an ecomimicry approach could optimise the multifunctional benefits of EGRs by supporting and conserving local biodiversity, as well as delivering ES such as urban cooling and stormwater attenuation. A study for the EU FP7 TURAS project (http://www.turas-cities.org/) demonstrated there was no associated ES cost in terms of water attenuation and thermal performance when biodiverse EGR systems were compared to industry-standard Sedum EGR designs (Connop et al. 2013), indicating that a biodiversity-focused approach need not compromise ES provision.

\section{The ecomimicry process for designing EGRs (and other UGI)}

A fundamental starting point for the proposed ecomimicry process is to read the local landscape, to determine important features. Where possible these should then be aspired to in the EGR design. Whilst reading the landscape requires ecological knowledge and expertise, this need not preclude non-specialists from using an ecomimicry approach. Valuable data can be gathered from a variety of sources such as academic research projects, local biodiversity action plans and ecological impact assessments for developments. A wealth of important ecological information and knowledge can also be accessed via organisations such as local Biological Records Centres, Wildlife Trusts and Natural History Societies. Online analytical tools can help to translate complex ecological data into more readily understandable material for nonspecialists involved in greenspace design (e.g. Webb et al. 2018) .

It is important to consider local underlying soils and substrates, their topography, hydrology and aspect, as well as regionally valuable plant and faunal communities as part of the ecomimicry design. Where possible, substrates used should reproduce similar conditions to those in the local landscape. From a sustainability perspective, this is best achieved by reusing substrate materials 
on site. Where this is not feasible or is unsuitable, for instance due to contamination, then locally-appropriate recycled aggregates should be sourced, and mixed with a suitable proportion of organic material such as compost (Molineux, Fentiman, and Gange 2009). Low-nutrient substrates with low organic content can be desirable for ecomimicry, as diverse communities often occur naturally on nutrient-poor soils, for example calcareous grasslands. Also, nutrientpoor substrates should reduce maintenance requirements because these conditions suppress competitive plant species associated with fertile habitats, and delay successional processes. Using locally typical substrates can be an important method for avoiding industry standardisation of EGR design, and research has shown that alternative aggregates can perform as well as the industry-standard crushed-brick substrate (Molineux, Fentiman, and Gange 2009).

Whilst this paper has a focus on how an ecomimicry approach can be applied to EGR design, constraints inherent to their construction (i.e. they have a relatively shallow substrate layer $<200$ $\mathrm{mm}$ ) means that some habitats cannot realistically be established on EGRs, for instance scrub and woodland. Furthermore, vertical isolation and the harsher environmental conditions at roof level will restrict colonisation and persistence of certain ecological communities on green roofs. Consequently, part of the ecomimicry process may filter out EGRs as an opportunity for habitat creation. Embedding ecomimicry in the design of landscaping at ground-level can then provide an opportunity to incorporate these additional locally-typical and ecologically valuable features into urban areas (Connop et al. 2011; Connop 2012; Nash 2017).

The 'habitat heterogeneity hypothesis', a cornerstone of ecological theory (MacArthur and MacArthur 1961), posits that structurally complex habitats provide a greater range of niches and resources, leading to an increase in species diversity. EGRs (and other UGI) designed to create a heterogeneous environment will therefore offer a broader variety of niches and provide opportunities for a wider range of biodiversity. Habitat heterogeneity can be achieved through diversifying substrate types and creating microtopography by profiling substrates at varying depths (Brenneisen 2003, 2006). Microsites and microclimates can also be increased through the provision of surface features such as deadwood piles, rubble and sand mounds (Gedge et al. 2012; Walker and Lundholm 2018), and even technological features such as PV panels (Nash et al. 2016). Figure 2 illustrates the process for achieving ecomimicry when designing EGRs and other UGI. 


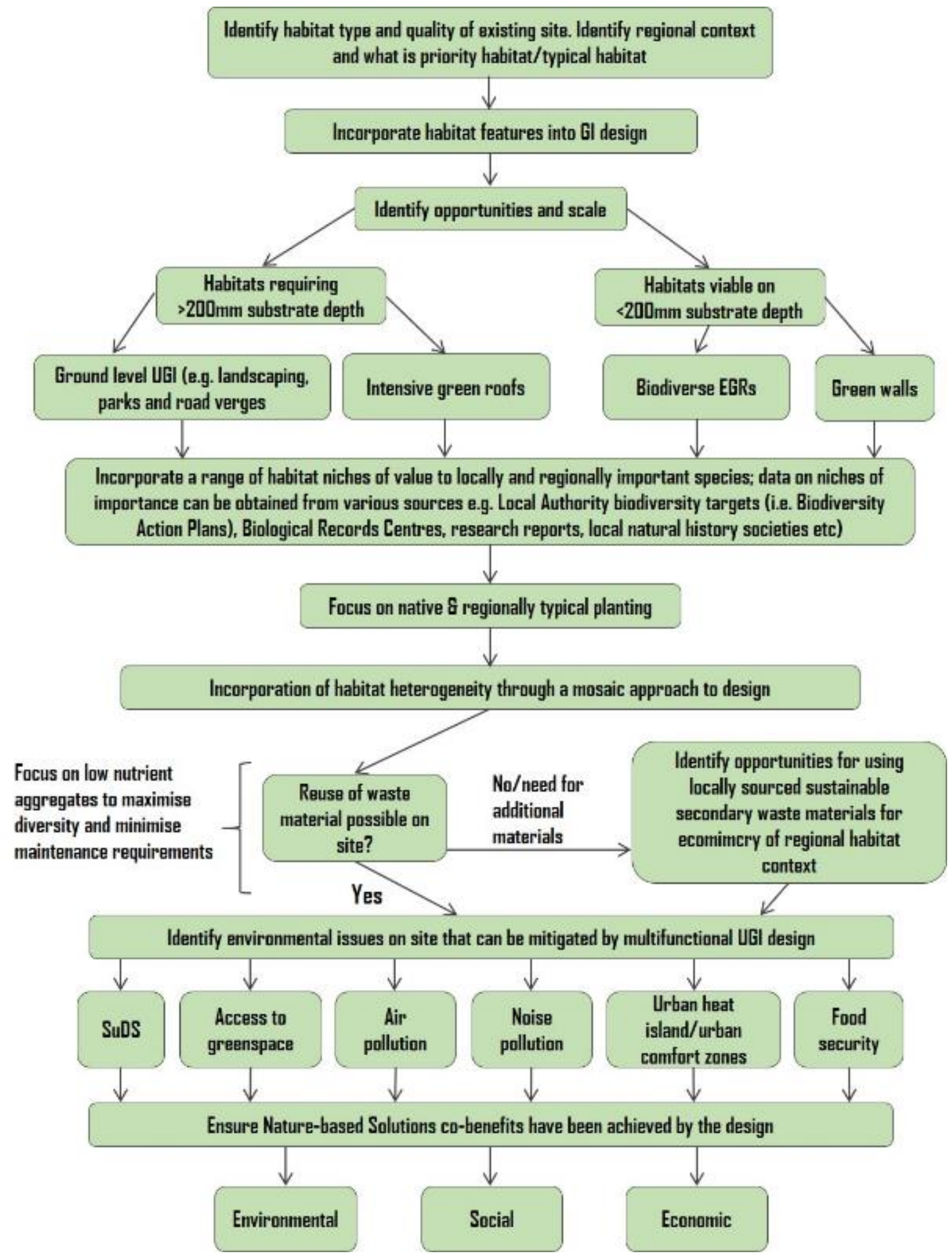

Figure 2. A framework for the ecomimicry process for EGR and UGI design. The framework presents the process of initially reading the local landscape to identify important habitats and features, then determining the appropriate form of UGI to deliver these habitats, including locally-appropriate plants and substrates, and incorporation of habitat heterogeneity. The framework illustrates how the ecomimicry approach to UGI design can deliver potential ES benefits and achieve the environmental, social and economic co-benefits of naturebased solutions. 


\section{Conceptual diagram for achieving ecomimicry in biodiverse EGR design}

Figure 3 provides a conceptual framework specifically illustrating how the ecomimicry process can be used to develop biodiverse EGR design, and the potential positive benefits that can be achieved by using this approach.

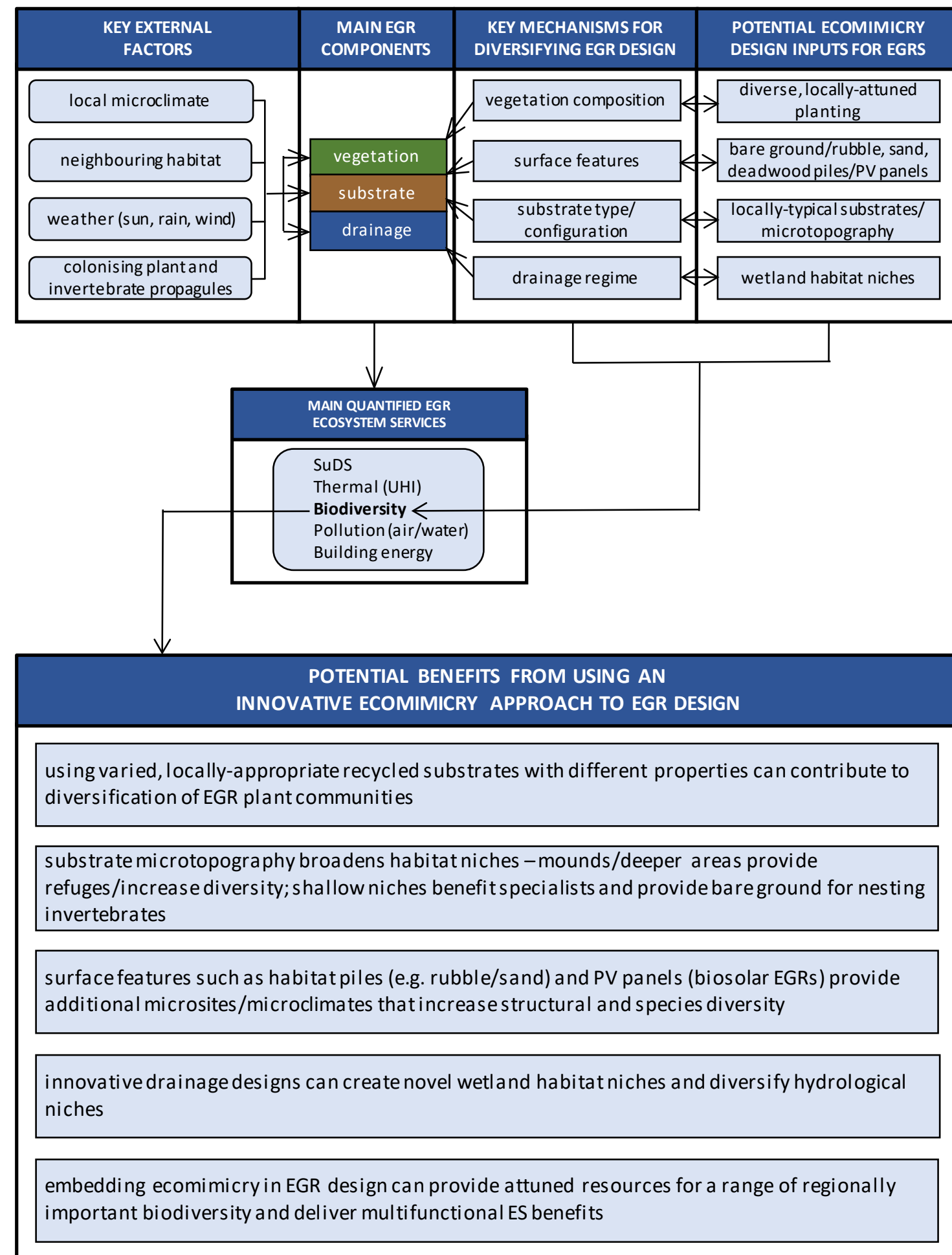

Figure 3. Conceptual framework illustrating the mechanisms and potential benefits of using an ecomimicry approach to EGR design. 
External factors such as the local microclimate and neighbouring habitats must be considered when designing EGRs, as these will play a major role in the ecological processes that govern the main EGR components: vegetation, substrate and drainage. This part of the ecomimicry conceptual framework can be understood in terms of the processes associated with ecological restoration practices. Restoration ecology is concerned with repairing or restoring degraded or lost habitats or ecosystems (Hobbs and Harris 2001). A principle of ecological restoration is to consider the landscape context, as this is interconnected and will influence recovery of the restored area and whether it becomes a functioning component of the landscape (Halle and Fattorini 2004). In the ecomimicry framework (Figure 3) this is represented by 'neighbouring habitat' and 'colonising plant and invertebrate propagules' within the 'key external factors' box. Assembly rules, a core concept in restoration, concerns how ecological communities develop, are structured and function and how (among other factors) biotic and abiotic ecological filters govern community development (Temperton and Hobbs 2004). In the ecomimicry model, some of these assembly rules have been considered and applied in a general way, for instance by including external abiotic factors such as the prevailing climate and local microclimate, and illustrating how substrate and drainage can be manipulated to filter habitat creation towards a desired state, in concert with appropriate, locally-attuned planting (which will undergo, to some extent, abiotic and biotic filtering). MacDonagh and Shanstrom 2015 provide a detailed example of using plant assembly rules to create prairie analogues on EGRs for Minnesota. Whilst in the strictest sense ecomimicry EGRs do not fulfil the definition of ecological restoration because of their novelty (Kinlock, Schindler \& Gurevitch, 2016), the ecomimicry approach could be viewed as a framework to facilitate urban ecological restoration goals, because it aims to deliver ecologically functioning habitats into disturbed urban environments, thereby potentially assisting with recovery of degraded urban ecosystems.

For green roof practitioners, redesigning key green roof components following ecomimicry principles should make it possible to create biodiverse EGRs that move away from industrystandard designs to provide more locally-contextualised roof top ecosystems. Using diverse and locally-attuned plants and substrates should help create locally-appropriate, ecologically functioning habitat resources for target regionally important biodiversity. A unified design approach that avoids the implementation of generic or homogenous EGRs could help to enhance the permeability of cities for biodiversity, and improve habitat connectivity for species dispersing through the urban matrix.

\section{Ecomimicry inspired by urban brownfield mosaics}

Ecomimicry does not necessarily aim to exactly replicate a habitat, instead the process can involve finding innovative and creative ways to recreate analogous conditions and functions of local habitat of nature conservation value. In this regard, the frameworks proposed for ecomimicry in this paper have been greatly informed by learning from the example of biodiverse brownfield sites. These sites are novel ecosystems, anthropogenic in origin and uniquely different from any naturally occurring habitats. Yet brownfield sites have become important reservoirs for biodiversity in the UK, particularly for species that can no longer find suitable resources in the natural landscape due to habitat loss or degradation (Harvey 2000; 
Roberts, Harvey and Jones 2006). Due to their anthropogenic origins, brownfield sites often have heterogeneous edaphic conditions, which drives the formation of unique habitat mosaics. Within the habitat mosaic, analogues of declining natural/semi-natural habitats are often represented, and these have become important refuges for biodiversity, including species of conservation concern (Gemmell and Connell 1984; Eversham, Roy, and Telfer 1996; Eyre, Luff, and Woodward 2003). Consequently, species typically associated with habitats such as sand dunes, heathlands and calcareous grassland have been recorded on disused sand and chalk quarry brownfield sites (Eyre, Luff, and Woodward 2003). Saltmarsh and fenland species have been found on flooded colliery spoil and inhabiting lagoons that form on waste fuel ash from power stations (Eversham, Roy, and Telfer 1996).

Evidence has shown that whilst brownfield sites often appear very distinct from native natural/semi-natural habitats, they can provide similar functions and niches, and offer an ecologically valuable analogue habitat (Gemmell and Connell 1984; Eversham, Roy, and Telfer 1996; Harvey 2000; Eyre, Luff, and Woodward 2003; Roberts, Harvey and Jones 2006). Furthermore, the brownfield mosaic, by its very nature, provides a heterogeneous environment that offers a broad array of niches, within which a rich diversity of species can coexist. These factors make brownfield habitats an excellent reference point for the ecomimicry design process for UGI, and demonstrate that it may not always be necessary to exactly replicate a natural habitat to deliver valuable ecological functionality for biodiversity. Proponents of reconciliation ecology (Rosenzweig 2003) advocate that UGI should not be constrained by conventional conservation paradigms such as restoration (Francis and Lorimer 2011) because urban ecosystems are essentially novel in character. By attempting to recreate and embed both locallycharacteristic, novel and (semi)natural habitat analogues into the fabric of urban areas, ecomimicry has parallels to, and builds on, the ideas of reconciliation ecology (Rosenzweig 2003; Francis and Lorimer 2011). Outside cities, traditional ecological restoration approaches may be more appropriate than ecomimicry for recreating and renewing habitats.

\section{IMPACT}

By using the ecomimicry frameworks outlined above, it should be possible to achieve biodiverse and multifunctional EGRs and UGI that provide broad ES. As such, adopting an ecomimicry approach to UGI design should help cities and urban developments meet sustainability targets (United Nations 2015), and contribute to the goals of no-net-loss of biodiversity and ES (European Commission 2012) during the development process. In a North American context, ecomimicry could offer a new experimental approach to biodiverse EGR design that could contribute to initiatives and strategies related to biodiversity conservation and management. For instance, the U.S. Fish and Wildlife Service's (FWS) Cooperative Recovery Initiative (CRI) is focused on actions that can contribute to the conservation of endangered and threatened species. As highlighted earlier in this paper, research has begun to show the potential value of EGRs as habitat for conservation priority endangered invertebrates (Kadas 2006; Brenneisen 2006). Using ecomimicry, EGR designs could be developed that are better attuned the ecological requirements of declining North American species whose habitat is being lost to urban development, in accordance with CRI objectives. Similarly, ecomimicry designed EGRs 
could also contribute to the FWS Urban Wildlife Conservation Program, by providing urban rooftop refuges and habitat stepping stones for wildlife within the places that city dwellers live, work and play, and offer an innovative tool for delivering community conservation education. Toronto, Canada is one of the few cities globally to have both a policy requiring construction of green roofs on new development projects and a guidance document on best practice for designing biodiverse EGRs (Bass et al. 2013). The ecomimicry frameworks outlined in this paper offer an additional model for creating locally-attuned habitats and promoting biodiversity on EGRs that could augment Toronto's existing best practice guidelines.

Research experimentally testing and monitoring the ecomimicry design approach has provided positive results, indicating it can produce ecologically functioning greenspace of value to target regionally-important biodiversity (Connop et al. 2016; Nash 2017). Nonetheless, more research is needed to trial and monitor locally-contextualised habitat designs, to build upon the evidence generated from these studies, and evaluate local systems in other regions. Scientific studies trialling an ecomimicry approach to EGR design in various ecoregions could evaluate the effectiveness of this process as a tool to develop regionally-attuned, sustainable EGR designs. For optimum accuracy, this would require repeated and detailed monitoring of replicated, rooflevel experimental projects, to generate a quantitative and qualitative evidence-base of performance, and develop regionally-attuned design guidance for green roof practitioners. Developing a more comprehensive understanding of the ecological outcomes of using an ecomimicry approach to designing EGRs, particularly through long-term ecological research, would be invaluable for understanding the potential role EGRs can play in providing suitable resources for species from target natural ecosystems (Williams, Lundholm, and MacIvor 2014).

In Europe, policy has progressed from a green infrastructure strategy to a Nature-based Solutions (NBS) approach (European Commission 2015) that brings together ecosystems-based strategies (such as blue-green infrastructure) with assessments of social and economic benefits (Raymond et al. 2017). Whilst the focus of this paper is on the biodiversity benefits of an ecomimicry approach, co-creation is also a fundamental goal of this process. Numerous different stakeholders, for instance architects, green roof designers, local authorities and local communities, must be engaged with designing and developing EGRs and other UGI/NBS to secure support for the principle of tackling environmental, social and economic challenges by renaturing cities (Connop et al. 2016). Collaboration between scientists and urban designers (e.g. architects, engineers and planners) could foster greater understanding for the value of integrating ecological functionality into EGR design and help overcome barriers to biodiverse EGR implementation. Embedding ecomimicry in the design process of EGR and NBS creation can provide a mechanism to facilitate locally-attuned renaturing, and could help to enhance cobenefits and minimise trade-offs. Ecomimicry could be used to unlock the full biodiversity potential of EGRs and other UGI in cities, creating functioning ecosystems grounded in a detailed understanding of urban ecological processes. Conserving urban biodiversity through ecomimicry should increase opportunities for urban communities to reconnect with nature, and improve the quality of life for people in cities. 


\section{LITERATURE CITED}

Alexandri, E. and Jones, P. 2008. "Temperature Decreases in an Urban Canyon due to Green Walls and Green Roofs in Diverse Climates.” Building and Environment 43: 480-93. https://doi.org/10.1016/j.buildenv.2006.10.055.

Balvanera, P., Pfisterer, A.B., Buchmann, N., He, J.S., Nakashizuka, T., Raffaelli, D. and Schmid, B. 2006. "Quantifying the Evidence for Biodiversity Effects on Ecosystem Functioning and Services.” Ecology Letters 9 (10): 1146-56. https://doi.org/10.1111/j.1461-0248.2006.00963.x.

Bass, B., MacIvor, J.S., Mcglade, T. and Toronto City Planning Division. 2013. "City of Toronto Guidelines for Biodiverse Green Roofs.”

Benyus, J. 1997. Biomimicry: Innovation Inspired by Nature. New York: Harper Collins.

Blank, L., Vasl, A., Levy, S., Grant, G., Kadas, G., Dafni, A. and Blaustein, L. 2013. "Directions in Green Roof Research: A Bibliometric Study.” Building and Environment 66: 23-28. https://doi.org/10.1016/j.buildenv.2013.04.017.

Blanusa, T., Monteiro, M.M.V., Fantozzi, F., Vysini, E., Li, Y. and Cameron, R.W. 2013. "Alternatives to Sedum on Green Roofs: Can Broad Leaf Perennial Plants Offer Better 'Cooling Service'?” Building and Environment 59: 99-106. https://doi.org/10.1016/j.buildenv.2012.08.011.

Bonthoux, S., Brun, M., Di Pietro, F., Greulich, S. and Bouché-Pillon, S. 2014. "How Can Wastelands Promote Biodiversity in Cities? A Review.” Landscape and Urban Planning 132: 79-88. https://doi.org/10.1016/j.landurbplan.2014.08.010.

Bowler, D.E., Buyung-Ali, L., Knight, T.M. and Pullin, A.S. 2010. "Urban Greening to Cool Towns and Cities : A Systematic Review of the Empirical Evidence." Landscape and Urban Planning 97 (3): 147-55. https://doi.org/10.1016/j.landurbplan.2010.05.006.

Brenneisen, S. 2003. “Green Roofs. How Nature Returns to the City.” In Greening Rooftops for Sustainable Cities.

—. 2006. "Space for Urban Wildlife: Designing Green Roofs as Habitats in Switzerland.” Urban Habitats 4 (1): 27-36.

Cardinale, B.J., Duffy, J.E., Gonzalez, A., Hooper, D.U., Perrings, C., Venail, P., Narwani, A., Mace, G.M., Tilman, D., Wardle, D.A. and Kinzig, A.P. 2012. "Biodiversity Loss and Its Impact on Humanity.” Nature 486 (7401): 59-67. https://doi.org/10.1038/nature11148.

Castleton, H. F., Stovin, V. Beck, S. and Davison, J. 2010. "Green Roofs; Building Energy Savings and the Potential for Retrofit.” Energy and Buildings 42 (10): 1582-91. https://doi.org/10.1016/j.enbuild.2010.05.004.

Coffman, R. and Waite, T. 2011. "Vegetated Roofs as Reconciled Habitats : Rapid Assays Beyond Mere Species Counts.” Urban Habitats 6.

Connop, S., Lindsay, R., Freeman, J. \& Kadas, G. 2011. "Barking Riverside: Office Landscaping for 
Biodiversity.” Essex Naturalist 28: 49-67.

Connop, S. 2012. “The Beetle Bump: Innovative Urban Habitat Creation for Rare Insects.” Essex Naturalist 29: 89-94.

Connop, S., Gedge, D., Kadas, G., Nash, C., Owczarek, K. and Newport, D. 2013. “TURAS Green Roof Design Guidelines: Maximising Ecosystem Service Provision through Regional Design for Biodiversity.”

Connop, S., Vandergert, P., Eisenberg, B., Collier, M.J., Nash, C., Clough, J. and Newport, D. 2016. "Renaturing Cities Using a Regionally-Focused Biodiversity-Led Multifunctional Benefits Approach to Urban Green Infrastructure.” Environmental Science and Policy 62 (2016): 99-111. https://doi.org/10.1016/j.envsci.2016.01.013.

Cook-Patton, S. C. and Bauerle, T.L. 2012. "Potential Benefits of Plant Diversity on Vegetated Roofs: A Literature Review.” Journal of Environmental Management 106: 85-92. https://doi.org/10.1016/j.jenvman.2012.04.003.

Dallimer, M., Tang, Z., Bibby, P. R., Brindley, P., Gaston, K. J. and Davies, Z. G. 2011. “Temporal Changes in Greenspace in a Highly Urbanized Region.” Biology Letters 7 (5): 763-66. https://doi.org/10.1098/rsbl.2011.0025.

Dvorak, B. and Volder, A. 2010. "Landscape and Urban Planning Green Roof Vegetation for North American Ecoregions : A Literature Review." Landscape and Urban Planning 96 (4): 197-213. https://doi.org/10.1016/j.landurbplan.2010.04.009.

European Commission. 2012. “EU Biodiversity Strategy to 2020.” Brussels.

—. 2015. "Nature-Based Solutions \& Re-Naturing Cities.” Brussels. https://doi.org/10.2777/765301.

Eversham, B., Roy, D. and Telfer, M. 1996. "Urban, Industrial and Other Manmade Sites as Analogues of Natural Habitats for Carabidae.” Annales Zoologici Fennici 33 (c): 149-56. https://doi.org/10.1234/12345678.

Eyre, M. D., Luff, M. L. and Woodward, J. C. 2003. "Beetles (Coleoptera) on Brownfield Sites in England: An Important Conservation Resource?” Journal of Insect Conservation 7 (4): 223-31. https://doi.org/10.1023/B:JICO.0000021020.66549.1e.

Francis, R. A. and Lorimer, J. 2011. "Urban Reconciliation Ecology: The Potential of Living Roofs and Walls.” Journal of Environmental Management 92 (6): 1429-37. https://doi.org/10.1016/j.jenvman.2011.01.012.

Gedge, Dusty. 2003. ““... From Rubble To Redstarts ....” In First Annual Greening Rooftops for Sustainable Communities Conference, Chicago, 2003.

Gedge, D., Grant,G. Kadas, G. and Dinham, C. 2012. “Creating Green Roofs for Invertebrates.” Buglife.

Gemmell, R.P. \& Connell, R.K. 1984. “Conservation and Creation of Wildlife Habitats in Industrial 
Land in Greater Manchester.” Landscape Planning 11: 175-86.

Grant, G., Engleback, L. and Nicholson, B.. 2003. "Green Roofs: Their Existing Status and Potential for Conserving Biodiversity in Urban Areas.” English Nature.

Halle, S. and Fattorini, M. 2004. "Advances in Restoration Ecology: Insights from Aquatic and Terrestrial Ecosystems.” In Assembly Rules and Restoration Ecology-Bridging the Gap between Theory and Practice, 10-33.

Harvey, P.R. 2000. "The East Thames Corridor: A Nationally Important Invertebrate Fauna under Threat.” British Wildlife 12: 91-98.

Hobbs, R J, and Harris, J A. 2001. "Restoration Ecology : Repairing the Earth' S Ecosystems in the New Millennium.” Restoration Ecology 9 (2): 239-46.

Ishimatsu, K. and Ito, K. 2013. "Brown/biodiverse Roofs: A Conservation Action for Threatened Brownfields to Support Urban Biodiversity.” Landscape and Ecological Engineering 9 (2): 299304. https://doi.org/10.1007/s11355-011-0186-8.

Jungels, J., Rakow, D.A., Allred, S.B. \& Skelly, S.M. 2013. “Attitudes and Aesthetic Reactions toward Green Roofs in Northeastern United States.” Landscape \& Urban Planning 117: 13-21.

Kadas, G. 2006. “Rare Invertebrates Colonising Green Roofs in London.” UrbanHabitats 4: 66-86.

Kinlock, N., Schindler, B.Y., and Gurevitch, J. 2016. "Biological invasions in the context of green roofs." Israel Journal of Ecology and Evolution 62 (1-2): 32-43.

Klein, P. and Coffman, R. 2015. "Science of the Total Environment Establishment and Performance of an Experimental Green Roof under Extreme Climatic Conditions.” Science of the Total Environment 512-513: 82-93. https://doi.org/10.1016/j.scitotenv.2015.01.020.

Larson, D. W., Matthes, U., Kelly, P.E., Lundholm, J.T. \& Gerrath, J.A. 2004. The Urban Cliff Revolution. Toronto: Fitzhenry \& Whiteside. Toronto: Fitzhenry and Whiteside.

Lepczyk, C.A., Aronson, M., Evans, K.L, Goddard, M.A., Lerman, S.B. and Macivor, J.S. 2017. "Biodiversity in the City: Fundamental Questions for Understanding the Ecology of Urban Green Spaces for Biodiversity Conservation.” BioScience 67 (9): 799-807. https://doi.org/10.1093/biosci/bix079.

Lundholm, J.T., Macivor,J.S., Macdougall, Z. and Ranalli, M.. 2010. "Plant Species and Functional Group Combinations Affect Green Roof Ecosystem Functions.” PlosOne 5 (3): 1-11. https://doi.org/10.1371/journal.pone.0009677.

Lundholm, J.T. 2006. "Green Roofs and Facades : A Habitat Template Approach.” Urban Habitats 4 (1): 87-101.

Lundholm, J.T, and Walker, E.A. 2018. "Evaluating the Habitat-Template Approach Applied to Green Roofs.” Urban Naturalist 1: 39-51.

MacArthur, R.H. \& MacArthur, J.W. 1961. “On Bird Species Diversity.” Ecology 42: 594-98. 
MacDonagh, L.P. and Shanstrom, N. 2015. “Assembling Prairie Biome Plants for Minnesota Green Roofs.” In Green Roof Ecosystems, edited by Richard K Sutton, 257-83. Springer International.

MacIvor, J.S., Ruttan, A. and Salehi, B. 2015. "Exotics on Exotics: Pollen Analysis of Urban Bees Visiting Sedum on a Green Roof.” Urban Ecosystems 18 (2): 419-30. https://doi.org/10.1007/s11252-014-0408-6.

MacIvor, J.S, Ranalli, M.A. and Lundholm, J.T. 2011. "Performance of Dryland and Wetland Plant Species on Extensive Green Roofs.” Annals of Botany 107: 671-79. https://doi.org/10.1093/aob/mcr007.

Mandel, L., McCoy, E. and Liss, T. 2016. "Reference Community : Adapting Native Plants to North American Green Roofs.” Journal of Green Building 11 (4): 15-36. https://doi.org/10.3992/jgb.11.4.15.1.

Marshall, M. 2007. “The Theory and Practice of Ecomimicry.” 3. Working Paper Series.

Millennium Ecosystem Assessment. 2005. “Ecosystems and Human Well-Being: Synthesis.” https://doi.org/10.1196/annals.1439.003.

Molineux, C.J., Fentiman, C.H. and Gange, A.C. 2009. "Characterising Alternative Recycled Waste Materials for Use as Green Roof Growing Media in the U.K.” Ecological Engineering 35 (10): 1507-13. https://doi.org/10.1016/j.ecoleng.2009.06.010.

Monterusso, M.A., Bradley Rowe, D. and Rugh, C.L. 2005. "Establishment and Persistence of Sedum Spp. and Native Taxa for Green Roof Applications.” HortScience 40 (2): 391-96.

Moulton, N. \& Gedge, D. 2017. “The UK Green Roof Market Report,” no. July.

Nagase, A. and Dunnett, N. 2012. "Landscape and Urban Planning Amount of Water Runoff from Different Vegetation Types on Extensive Green Roofs : Effects of Plant Species, Diversity and Plant Structure.” Landscape and Urban Planning 104 (3-4): 356-63. https://doi.org/10.1016/j.landurbplan.2011.11.001.

Nagase, A. and Tashiro-Ishii, Y. 2018. "Habitat Template Approach for Green Roofs Using a Native Rocky Sea Coast Plant Community in Japan.” Journal of Environmental Management 206: 25565. https://doi.org/10.1016/j.jenvman.2017.10.001.

Nash, C. 2017. "Brownfield-Inspired Green Infrastructure: A New Approach to Urban Biodiversity Conservation.”

Nash, C., Clough, J., Gedge, D., Lindsay, R., Newport, D., Ciupala, M. A. and Connop, S. 2016. "Initial Insights on the Biodiversity Potential of Biosolar Roofs: A London Olympic Park Green Roof Case Study.” Israel Journal of Ecology and Evolution 62 (1-2): 74-87. https://doi.org/10.1080/15659801.2015.1045791.

Oberndorfer, E., Lundholm, J., Bass, B., Coffman, R.R., Doshi, H., Dunnett, N., Gaffin, S., Kohler, M., Lui, K.Y. \& Rowe, B. 2007. "Green Roofs as Urban Ecosystems : Ecological Structures , Functions , and Services.” BioScience 57 (November): 823-34. 
Pearce, H, and Walters C. 2012. "Do Green Roofs Provide Habitat for Bats in Urban Areas ?" Acta Chiropterologica 14 (2): 469-78. https://doi.org/10.3161/150811012X661774.

Raymond, C. M., Frantzeskaki, N., Kabisch, N., Berry, P., Breil, M., Razvan Nita, M., Geneletti, D. and Calfapietra, C. 2017. "A Framework for Assessing and Implementing the Co-Benefits of Nature-Based Solutions in Urban Areas.” Environmental Science and Policy 77 (July): 15-24. https://doi.org/10.1016/j.envsci.2017.07.008.

Rayner, J.P, Farrell, C., Raynor, K.J. Murphy, S.M. and Williams, N.S.G. 2016. "Plant Establishment on a Green Roof under Extreme Hot and Dry Conditions : The Importance of Leaf Succulence in Plant Selection.” Urban Forestry \& Urban Greening 15: 6-14. https://doi.org/10.1016/j.ufug.2015.11.004.

Roberts, J., Harvey, P. \& Jones, R. 2006. “All of a Buzz in the Thames Gateway. Phase 1: Identification of the Brownfield Resource and Preliminary Assessment of the Invertebrate Interest.”

Rosenzweig, M.L. 2003. Win-Win Ecology: How the Earth's Species Can Survive in the Midst of Human Enterprise. Oxford: Oxford University Press.

Rumble, H., and Gange, A.C. 2013. "Soil Microarthropod Community Dynamics in Extensive Green Roofs.” Ecological Engineering 57: 197-204. https://doi.org/10.1016/j.ecoleng.2013.04.012.

Schroll, E., Lambrinos, J., Righetti, T. and Sandrock, D. 2011. "The Role of Vegetation in Regulating Stormwater Runoff from Green Roofs in a Winter Rainfall Climate.” Ecological Engineering 37 (4): 595-600. https://doi.org/10.1016/j.ecoleng.2010.12.020.

Snodgrass, E.C. \& Snodgrass, L.L. 2006. Green Roof Plants. Portland, Oregon: Timber Press Inc.

Speak, A.F., Rothwell, J.J., Lindley, S .J. and Smith, C.L. 2012. "Urban Particulate Pollution Reduction by Four Species of Green Roof Vegetation in a UK City.” Atmospheric Environment 61: 283-93. https://doi.org/10.1016/j.atmosenv.2012.07.043.

Susca, T., Gaffin, S.R. and Dell’Osso, G.R. 2011. "Positive Effects of Vegetation : Urban Heat Island and Green Roofs.” Environmental Pollution 159: 2119-26. https://doi.org/10.1016/j.envpol.2011.03.007.

Sutton, R.K. 2015. Green Roof Ecosystems. New York: Springer International.

Sutton, R.K., Harrington, J.A., Skabelund, L., Macdonagh, L.P, Coffman, R. and Koch, G. 2012. "Prairie-Based Green Roofs: Literature, Templates, and Analogs.” Journal of Green Building 7 (0): 143-72. https://doi.org/10.3992/jgb.7.1.143.

Sutton, R.K. 2008. “Media Modifications for Native Plant Asemblages on Extensive Green Roofs.” In Sixth Annual Greening Rooftops for Sustainable Communities Conference. Baltimore.

. 2013. "Seeding Green Roofs with Native Grasses.” Journal of Living Architecture 1 (1): 1535.

Temperton, V.M., and Hobbs, R. 2004. “The Search for Ecological Assembly Rules and Its Relevance 
to Restoration Ecology.” In Assembly Rules and Restoration Ecology-Bridging the Gap between Theory and Practice2, 34-54.

Thuring, C. \& Grant, G. 2016. “The Biodiversity of Temperate Extensive Green Roofs - a Review of Research and Practice.” Israel Journal of Ecology \& Evolution 62: 44-57.

Tonietto, R., Fant, J., Ascher,J., Ellis, K. and Larkin, D. 2011. "Landscape and Urban Planning A Comparison of Bee Communities of Chicago Green Roofs , Parks and Prairies.” Landscape and Urban Planning 103 (1): 102-8. https://doi.org/10.1016/j.landurbplan.2011.07.004.

United Nations. 2015. “Transforming Our World: The 2030 Agenda for Sustainable Development.” General Assembley 70 Session 16301 (October): 1-35. https://doi.org/10.1007/s13398-0140173-7.2.

Van Mechelen, C., Dutoit, T. and Hermy, M. 2014. "Landscape and Urban Planning Mediterranean Open Habitat Vegetation Offers Great Potential for Extensive Green Roof Design.” Landscape and Urban Planning 121: 81-91. https://doi.org/10.1016/j.landurbplan.2013.09.010.

Walker, E.A, and Lundholm, J.T.. 2018. "Designed Habitat Heterogeneity on Green Roofs Increases Seedling Survival but Not Plant Species Diversity.” Journal of Applied Ecology 55 (2): 694704. https://doi.org/10.1111/1365-2664.12970.

Webb, J., Heaver, D., Lott, D., Dean, H.J., van Breda, J., Curson, J., Harvey, M.C., Gurney, M., Roy, D.B., van Breda, A., Drake, M., Alexander, K.N.A. and Foster, G. 2018. "Pantheon - Database Version 3.7.6.” 2018. http://www.brc.ac.uk/pantheon/.

Williams, N.S.G., Lundholm,J.T. and Macivor, J.S. 2014. “Do Green Roofs Help Urban Biodiversity Conservation?” Journal of Applied Ecology 51 (6): 1643-49. https://doi.org/10.1111/13652664.12333.

Williams, N.S.G., Rayner, J.P and Raynor, K.J. 2010. "Green Roofs for a Wide Brown Land : Opportunities and Barriers for Rooftop Greening in Australia.” Urban Forestry and Urban Greening 9 (3): 245-51. https://doi.org/10.1016/j.ufug.2010.01.005.

Wong, N.H., Chen, Y., Ong, C.L. and Sia, A. 2003. "Investigation of Thermal Benefits of Rooftop Garden in the Tropical Environment.” Building and Environment 38 (2): 261-70. https://doi.org/10.1016/S0360-1323(02)00066-5. 